\title{
O indivíduo e o meio social na formação da identidade homossexual
}

\author{
Identidade homossexual e \\ normas sociais: histórias de vida.
}

SELL, Teresa Adada.

2. ed. rev. e ampl. Florianópolis: EDUFSC, 2006. $255 \mathrm{p}$.

Alinhada com pesquisas atuais que usam as teorias queer ${ }^{1}$ como base de investigação, Teresa Sell, ex-professora do Departamento de Psicologia da Universidade Federal de Santa Catarina (UFSC), desenvolve uma pesquisa histórica e marcante sobre a identidade homossexual a partir de entrevistas com homossexuais masculinos em Florianópolis, Santa Catarina, na década de 1980, quando pesquisas sobre (homo)sexualidade no Brasil ainda eram bastante incipientes. Tendo sido publicado primeiramente em 1987, fruto de sua pesquisa de mestrado em Psicologia Social pela Universidade de São Paulo (USP), este livro, reapresentado em uma edição revisada e ampliada, interessa àqueles que desenvolvem pesquisas sobre identidades de gênero, bem como a todos que queiram compreender melhor a complexidade e as nuances presentes na formação do indivíduo como ser social.

Já na Introdução a autora destaca a heterogeneidade do rótulo 'homossexual', visto que toda sua obra baseia-se exatamente na noção de homossexualidades como experiências individuais, que podem compartilhar características comuns, mas que são formadas a partir de contextos sociais específicos, o que motiva a rejeição de qualquer essencialismo conceitual. Nessa seção, também são explicitados alguns elementos metodológicos, tais como a seleção dos entrevistados, a (não) identificação deles, bem como a forma de condução das entrevistas. Por ser uma reedição ampliada, Sell apresenta também colocações atuais a respeito do posicionamento do poder público com relação aos homossexuais, destacando investimentos em eventos destinados a esse público, mas também fazendo a ressalva de que boa parte da difícil realidade vivida no momento da condução das entrevistas ainda persiste na atualidade. Ademais, traz colocações acerca da AIDS, já que seu advento no Brasil se deu posteriormente à publicação da primeira edição deste livro. Sobre esse tema, a autora afirma que, apesar de não ser mais possível "associar AIDS com homossexualismo, o estigma, porque de fato é uma marca, permaneceu" (p. 22).

O livro é dividido em duas partes, que, por sua vez, são subdividas em três e cinco capítulos, respectivamente. Na primeira parte, em seu primeiro capítulo, alguns conceitos são discutidos, tais como a formação da identidade, que se dá no meio social, ${ }^{2}$ visto que esse é anterior ao próprio indivíduo, isto é, há elementos inerentes ao ser humano, mas "a natureza é modelada pelos valores e padrões da cultura" (p. 30). Dessa forma, vemos, no segundo capítulo, que é exatamente no confronto entre o indivíduo e os valores tradicionais de seu grupo social que as divergências e os conflitos surgem. Tendo em vista que vivemos em uma sociedade que, em grande parte, ainda tem a heterossexualidade como único modo legítimo de vivenciar a sexualidade, encontramos aí o cerne da rejeição à homossexualidade, pois é vista como desviante e, portanto, inaceitável. Essa problemática é revelada, no terceiro capítulo, em quinze entrevistas, que foram conduzidas com muito respeito, o que permitiu que os entrevistados falassem de forma aberta sobre suas experiências de vida. Essas entrevistas demonstraram que a homossexualidade é vivida de formas diversas, apesar de várias questões serem compartilhadas por entrevistados que tinham histórias de vida bem diferentes. Além disso, podemos observar a atualidade de várias das questões discutidas nas entrevistas, o que demonstra que muitas preocupações, dificuldades e valores daquela década ainda persistem em nossa sociedade. 
Na segunda parte do livro, Sell discute pontos importantes dos relatos, entrelaçandoos com uma discussão teórica leve, porém consistente. No primeiro capítulo, a autora destaca algo que realmente é uma constante nas entrevistas: o fato de a identidade ser formada "na relação do Eu com o Outro" (p. 181), visto que muitos dos entrevistados falaram de suas experiências e opiniões a partir de uma contraposição com a heterossexualidade. Os comportamentos foram descritos como desviantes do esperado pela sociedade, o que causou muita angústia ao se perceberem 'diferentes', gerando, ainda, culpa e vergonha pela noção subsequente de anormalidade. Vários entrevistados reforçaram a importância de se aceitarem para que os outros também pudessem aceitá-los. Além disso, a autora levanta a possibilidade de grupos discriminados se unirem para formar uma força maior que suas atitudes individuais, ${ }^{3}$ já que "a diversidade da natureza humana é maior do que as regras que ela criou" (p. 194). No segundo capítulo, o ocultamento da orientação sexual é apresentado, através das entrevistas, como um elemento fundamental na dinâmica do homossexual com a família e o grupo social, visto que o homossexual, em geral, deixa, no máximo, que desconfiem de sua orientação sexual sem que precise confirmá-la. Nessa reedição, Sell acrescenta que esse ocultamento foi drasticamente reforçado com a disseminação do vírus HIV, que ainda não tinha surgido quando as entrevistas foram feitas. Além disso, atualizando sua publicação, comenta a maior visibilidade do homossexual na TV, mas destaca que nem sempre a maneira como foram representados anteriormente contribuiu para o esclarecimento e a educação da população, e que, apesar de terem sido criados vários grupos de defesa do homossexual, a violência ainda é uma triste realidade a ser combatida. Acrescenta, ainda, que a internet aumentou a possibilidade de encontros e informação, ao mesmo tempo que também criou novos perigos. Por fim, enfatiza que, atualmente, o público gay representa uma fatia do mercado muito valiosa e exigente, e que eles, a partir de uma atuação organizada, também têm exercido justas pressões junto ao poder público para terem seus direitos reconhecidos e defendidos, inclusive o direito referente à união civil, um tema com "forte implicação política na conquista de cidadania por uma parcela significativa da população brasileira, que se reconhece como homossexual". ${ }^{4}$ Tal organização é demonstrada pelo fato de que "associações e grupos ativistas se multiplicam pelo País. Atualmente, há cerca de 140 grupos espalhados por todo o território nacional". ${ }^{5}$ Contudo, mesmo não tendo sido o foco da autora, também acredito ser importante registrar que essa luta por políticas públicas, apesar de ser muito legítima e dar visibilidade a uma parcela da sociedade organizada, também revela uma incompetência do próprio Poder Legislativo em tratar da questão.

Ainda na segunda parte, em seu terceiro capítulo, há o foco na dinâmica das relações sexuais entre heterossexuais e homossexuais, bem como desses entre si, discutindo-se as diferentes nuances e configurações que tais contatos podem assumir, dentre as quais fol destacada a bissexualidade. Ademais, problematiza-se a divisão entre ativos e passivos como uma reprodução da conhecida separação entre dominador (mais masculino) e dominado (mais feminino). Dessa forma, vê-se que essa divisão de papéis demonstra "a interligação da vida sexual com o contexto cultural e toda a influência sociopolítica da relação entre duas pessoas" (p. 223). No quarto capítulo, Sell afirma que nas entrevistas, independentemente do tipo de relação que era estabelecida, o amor estava "presente como uma possibilidade de paz, de suporte, de satisfação pessoal" (p. 228), apesar dos frequentes desencontros causados, em especial, pela intolerância com essa forma de relacionar-se com o Outro. No último capítulo, em suas considerações finais, mesmo as experiências femininas não constando deste livro, pelo fato da pouca disponibilidade para serem entrevistadas, a autora tece comentários comparativos com a vivência homossexual masculina a partir de apenas três entrevistas com mulheres.

Concluindo, destaco a relevância pública desta obra, visto que "conhecer sobre homossexualidade é conhecer sobre o comportamento heterossexual, pois ambas as formas se encontram ao tentarem se distinguir" (p. 244) e apresentam-se em diversas gradações, evitando-se, assim, o dualismo 'homossexual e heterossexual'. Contudo, também apresento ressalva à afirmação da autora de que nos grupos de 'iguais' não haveria a necessidade de "contínua defesa da identidade" (p. 38), porque há várias identidades homossexuais que precisam, sim, de reafirmação constante mesmo nesses ambientes, tais como a postura estereotipada do masculino (ativo) e do feminino (passivo). A autora encerra sua obra, revisada e ampliada depois de 20 anos de sua publicação, reafirmando a necessidade de um 
mundo mais justo, com oportunidades de livre expressão do amor e da sexualidade para todos, visto que, mesmo depois de conquistarem um espaço maior de visibilidade e respeito, os homossexuais ainda hoje enfrentam demonstrações de violência e intolerância. Por fim, cabe ressaltar, ainda, que essa mudança, muito mais do que através de leis, mesmo sendo elas essenciais, deve ser promovida por meio da educação e da reavaliação de nossos conceitos e atitudes diante do ser humano - independentemente da especificidade de sua conduta sexual.

\section{Notas}

${ }^{1}$ Teresa DE LAURETIS, 1991.

${ }^{2}$ Mara Coelho de Souza LAGO, 1999.

${ }^{3}$ Luiz Fernando Neves CÓRDOVA, 2006.

${ }^{4}$ Miriam Pillar GROSSI, 2003, p. 263.

${ }^{5}$ CONSELHO NACIONAL DE COMBATE À DISCRIMINAÇÃO, 2004 , p. 15.

\section{Referências bibliográficas}

CONSELHO NACIONAL DE COMBATE À DISCRIMINAÇÃO. Brasil sem homofobia: Programa de Combate à Violência e à Discriminação contra GLTB e Promoção da Cidadania Homossexual. Brasília: Ministério da Saúde, 2004.
CÓRDOVA, Luiz Fernando Neves. Trajetórias de homossexuais na ilha de Santa Catarina: temporalidades e espaços. 2006. Tese (Doutorado em Ciências Humanas) - Programa de Pós-Graduação Interdisciplinar em Ciências Humanas, Universidade Federal de Santa Catarina, Florianópolis, 2006.

DE LAURETIS, Teresa. "Queer Theory: Lesbian and Gay Sexualities." Differences: A Journal of Feminist Cultural Studies, Durham: Duke University Press, v. 3, n. 2, p. iii-xviii, 1991.

GROSSI, Miram Pillar. "Gênero e parentesco: famílias gays e lésbicas no Brasil". Cadernos Pagu, Campinas: Unicamp, n. 21, p. 261-280, 2003.

LAGO, Mara Coelho de Souza. "Identidade: a fragmentação do conceito". In: SILVA, Alcione Leite da; LAGO, Mara Coelho de Souza; RAMOS, Tânia Regina Oliveira (Org.) Falas de gênero: teoria, análises e leituras. Florianópolis: Editora Mulheres, 1999. p. 119 129.

Fábio Alexandre Silva Bezerra Universidade Federal de Santa Catarina 